\title{
Ambiguitas Aruna dan Paradoks Citarasa Lidahnya Poskolonialitas Novel Kuliner Laksmi Pamuntjak
}

\author{
Ary Budiyanto ${ }^{1}, \&$ Latifah $^{2}$ \\ ${ }^{1}$ Prodi Antropologi, FIB Universitas Brawijaya \\ ${ }^{2} \mathrm{STAB}$ Kertarajasa \\ arybudhi@ub.ac.ic;_efi.latifah@gmail.com
}

\begin{abstract}
How to cite (in APA Style):Budiyanto, A., \& Latifah, E. (2018). Ambiguitas aruna dan paradoks citarasa lidahnya poskolonialitas novel kuliner Laksmi Pamuntjak. Jurnal Pendidikan Bahasa dan Sastra, 18(2), doi:10.17509/bs_jpbsp.v18i2.15510
\end{abstract}

Article History: Received (15 Avril 2018); Revised (25 Auguts 2018); Accepted (01 October 2018).

Journal homepage: http:// ejournal.upi.edu./index.php/BS_JPBSP

\begin{abstract}
Abstrak: Makanan bukan hanya kebutuhan biologis mendasar manusia, namun juga merupakan situs kebudayaan yang menjadi medan pertarungan kekuasaan, identitas, sosial, dan kelas. Dunia makanan dan kulinernya adalah sebuah diskursus dan metafora kuasa, terlebih di bangsa-bangsa koloni pasca-kolonial. Novel Aruna dan Lidahnya karya Laksmi Pamuntjak merepresentasikan warisan poskolonial melalui mimikri, hibriditas, dan ambivalensi. Melalui close reading dan pendekatan poskolonial, tampak bahwa sastra kuliner ini menampilkan paradoksial, mengangkat khazanah kuliner lokal tradisional, namun memposisikannya di bawah masakan luar negeri di dalam ambiguitas pribadi Aruna dan ketiga kawannya. Hal ini membentuk citra kuliner lokal sebagai makanan kelas dua, yang berseberangan dengan citra makanan luar negeri yang sehat, bersih, dan berkelas. Sebagai bentuk revolusi mental, inferioritas konstruksi kolonial, terutama bidang kuliner, perlu terus dikritik sebagai bentuk apresiasi terhadap kekayaan keragaman budaya Nusantara.
\end{abstract}

Kata kunci: sastra kuliner; poskolonial; makanan lokal

\section{Aruna's Ambiguity and the Paradoxical Flavors of Her Tongue Poscoloniality of Laksmi Pamuntjak's Culinary Novel}

\begin{abstract}
Food is not only a basic human biological need, it is also a cultural site that is a battleground of power, identity, social, and class. The world of food and culinary is a discourse and metaphor of power, especially in the nations of the post-colonial colony. Aruna's novel and his tongue by Laksmi Pamuntjak represent the post-colonial heritage through mimicry, hybridity, and ambivalence. Through close reading and postcolonial approach, it appears that this culinary literature displays paradoxical, it raised traditional local culinary treasures but positions it under foreign cuisine in the personal ambiguity of Aruna and her friends. This forms the image of local culinary as a second-class meal, which is opposite to healthy, clean, and classy overseas food image. As a form of mental revolution, the inferiority of colonial construction, especially in the culinary field, should continue to be criticized as a form of appreciation of the rich diversity of the archipelago's culinary culture.
\end{abstract}

Keywords: culinary literature; poskolonial; local food 


\section{PENDAHULUAN}

Makanan bukan hanya terkait konsumsi yang membawa kesenangan atau sekadar bertahan hidup. Nilai budaya, agama, sosial, dan sejarah menentukan preferensi dan gaya makan kita. Diungkapkan oleh Massimo Montanari (2006), sejarawan kuliner, bahwa "food is culture when produced, prepared and eaten" dan dalam pengantar bukunya ini ditekankan pula bahwa "how it came to taste good and how it became metaphor and discourse." Artikel ini melihat bagaimana metafora dan diskursus dunia kuliner Indonesia poskolonial hadir dalam selera makanan dan makanan di tokohtokoh Novel Aruna dan Lidahnya. Sejarah panjang kolonialisasi bangsa Eropa di dunia yang membawa pengaruh besar pada dunia ekonomi dan politik juga mempengaruhi kebudayaan kuliner bangsa-bangsa koloninya. Dampak kolonisasi dalam sejarah makanan dan kulinerjuga merupakan proses kekerasan psikologis maupun material.Ia tidak hanya menyebabkan penderitaan fisik pada masanya berlangsung, seperti saat kulturestetsel atau tanam paksa masa Kolonial Belanda hingga perampasan beras pada masa pendudukan Jepang di Indonesia yang menyebabkan kelaparan kronis, namun juga berdampak secara mental dalam jangka waktu yang lebih panjang.Hal ini termasuk dalam masalah selera dan citarasa makanan.Sastra kuliner, Aruna dan Lidahnya, menunjukkan jejak-jejak poskolonialisme dalam bentuk mimikri, hibriditas, dan ambivalensi.

Dalam kajiannya tentang "Mimikri dalam Kuliner Indonesia melalui Kajian Poskolonial", Utami (2012,p. 815) mengelompokkan kuliner non-tradisional yang mencakup makanan hasil mimikri seperti selat solo, klappertart, dan manuk enom. Ia juga melihat bahwa proses mimikri ini juga kiblatnya bergeser dari kolonial Belanda menjadi Amerika.Dominasi media mempengaruhi proses hegemoni Barat di era neokolonialisme ini. Seperti yang diutarakan Utami, bentuk mimikri hasil hegemoni ini dapat disikapi secara positif dalam rangka memperkaya khazanah budaya Nusantara, namun juga perlu dilihat secara kritis karena perubahan kuliner berpengaruh kuat dalam pembentukan identitas.

"Food has always been a fundamental tool in the process of colonization," demikian kata Dr. Linda Alvarez. Alvarez (2018) melihat apa yang terjadi di Amerika Latin ketika kolonial Spanyol mempermasalahkan urusan makan mereka vis a vis dengan makanan masyarakat lokal jajahannya. Alvarez juga mengatakan bahwa seseorang tidak dapat memahami dengan tepat kolonialisasi tanpa melibatkan masalah makan dan makanan.Kolonial Eropa yakin bahwa superioritasnya dibentuk melalui makanan. Mereka takut akan menyerupai kaum terjajah bila mereka ikut memakan jenis-jenis makanan asli Pribumi. Mereka percaya bahwa hanya "makanan yang benar" (right foods) yang mampu melindungi mereka di tanah yang baru, tanah jajahan. Dalam hal ini, makanan bukan hanya berfungsi menjaga superioritas tubuh orang Eropa, melainkan juga mempertahankan identitas sosial.Peran makanan sebagai penanda kelas terlihat dari kecenderungan kaum elite Eropa dalam melihat sayuran berakar sebagai sesuatu yang kotor karena tumbuh di bawah tanah.Oleh karena itu, mereka lebih memilih memakan sayuran yang tumbuh di pohon, di ketinggian. Kelas atas Spanyol juga ditandai dengan bahan makanan mahal dalam menu sehari-hari mereka, yaitu daging, roti, dan anggur, sementara masyarakat kelas bawah Spanyol yang tidak mampu mengonsumsi bahan pangan itu cenderung mengonsumsi oat, gandum hitam, jelai, dan rebusan sayur. Saat mereka tinggal di tanah jajahan, mereka membawa konsep pemilahan budaya dan kelas berdasarkan makanan ini untuk menjaga superioritas di depan kaum Pribumi. Untuk mensejajarkan diri, masyarakat jajahan pun berupaya meniru pola "makan yang benar" kolonial itu, sehingga dalam beberapa tingkat menggeser identitas dan kearifan lokal kuliner lokal. Di sini Alvarez menegaskan bahwa kolonisasi 
adalah proses kekerasan yang secara mendasar mengubah cara hidup orangorang jajahan. Melalui norma makanan, tatanan sosial dan budaya disampaikan, dan juga dilanggar. Namun, kita tidak boleh lupa bahwa praktek penjajahan atau kolonisasi selalu tentang hal yang dikontestasikan sebagaimana kelompok-kelompok tersebut saling bernegosiasi ruang dalam proses ini. Hingga kini, makanan asli tetap ada dalam makanan Amerika Latin kontemporer sebagaimana juga dengan makanan Eropa. Seperti halnya di Amerika Latin, hal sama juga terjadi di Indonesia meskipun terdapat perbedaan. Identitas poskolonial mereka masih dapat berjumpa dengan mantan Tuan mereka sehari-hari, sementara budaya dan masyarakat creole yang hibrid dari perjumpaan kolonial dan lokal masih terjadi. Hal itu tidak ada lagi dalam era poskolonial Indonesia. Kini sang Tuan kolonial telah menghilang dan bangsa hibrid telah dipaksa lebur dalam proses asimilasi dan akulturasi yang didengungkan oleh Sukarno dan digilaskan oleh Suharto (Poerwanto, 1999).

Hilangnya Tuan Kolonial telah menaikkan bangsa ini menjadi Tuan di negeri sendiri, namun dorongan untuk ingin sejajar dengan bangsa Tuan Kolonial masih terus bersemayam dibawah sadar anak bangsa. Paradoksnya, meskipun masa kolonial itu telah berlalu, sikap mental inferior khas kelas terjajah itulah yang menjadi dorongan untuk mencapai kesejajaran- mentalitas "Indo" dalam pandangan Romo Mangunwijaya (Mangunwijaya 1986,p.104). Seringkali kita dengar jargon "untuk menjadi modern, world-class, agar tidak malu di mata dunia, apa kata dunia" keluar dari mulut para intelektual, penguasa, agamawan, dan politisi yang seakan menjadi obsesi bangsa ini. Tak terelakkan, dalam budaya kuliner pun bangsa ini masih mencari kesejajaran dengan dunia Barat, tempat bangsa Tuannya berasal, maka cafe dan resto membanjiri kota-kota besar di pelosok negeri ini- menggeser warung dan restoran tradisional. Para penjual nasi pecel dan nasi- nasi lain yang dahulu begitu meriah menawarkan jajaannya di stasiun-stasiun kereta dan bus kini diusir, menghilang, punah digantikan dengan citarasa modern asing seperti Roti 'O, KFC, CFC, Roti Maryam dan kedai kopi dengan gaya Starbuck. Yang tradisional tetap terpinggirkan, berada di luar stasiun dan mall yang modern dengan wifi, bersih, lebih cozy dan berkelas. Sementara itu, yang tradisional menjadi sinonim keliaran, ndesa, kampungan, kotor, jorok dan udik yang selalu terancam oleh otoritas atas nama etika dan estetika kota modern: kebersihan dan keindahan kota. Sebuah paradoks dari euforia kebijakan kepariwisataan yang ingin meningkatkan devisa turisme dari dunia kuliner tradisional. Dalam sastra kuliner di Indonesia kontemporer apakah hal itu terjadi juga? Hal ini menarik untuk dilihat dalam novel Laksmi Pamuntjakyang dinobatkan sebagai novel kuliner yang fenomenal pada 2014 ini.

Budaya kuliner Nusantara telah banyak menjadi objek kajian seiring dengan meningkatnya karya-karya sastra gastronomidalam khazanah sastra Indonesia. Bramantio (2013) melakukan perenungan tentang keindonesiaan berdasarkan puitika tiga cerpen berbasis kuliner:"Filosofi Kopi", "Madre", dan "Smokol". Dalam pembacaannya ini, Bramantioingin bergerak dari perspektif gastronomi ke gastrosofi untuk mengambil makna yang lebih mendalam - filosofis-dari budaya kuliner di tiga cerpen tersebut. Dengan demikian, ia menyimpulkan bahwa ketiga cerpen tersebut menggambarkan Indonesia yang cerah, penuh pengharapan, karena anak muda urbannya yang masih mau menggali nilai-nilai tradisional, terutama dalam tradisi kuliner. Simpulan Bramantio ini sedikit berbeda jika dilihat dengan kacamata poskolonial mengingat dua cerpen kuliner Dee sebenarnya tidak begitu mengIndonesia dibandingkan dengan "Smokol". "Filosofi Kopi" karya Dee memang menemukan kesederhanaan Indonesia di Kopi Tiwus, mengingatkan akan 
ambivalensi mencari identitas asli ditengah arus asing dan global di cafe urban. Sementara hibriditas "Madre" dan dunia patisserie Eropa kolonial tetap hidup dalam darah dan ranah creole, peranakan Tionghoa dan setengah India, dan dengan konsumen ekspatriat urban yang masih hadir sebagai konsumen raja di bangsa ini. Di sisi lain, cerpen makan besar "Smokol" menemukan ironi realitas yang nyinyir atas kelaparan di negeri yang katanya makmur ini. Jadi, dapat dilihat dalam perspektif poskolonial bahwa apa yang Bramantio lihat pada generasi muda urban Indonesia positif, cerah, penuh pengharapan, karena masih berhasrat menggali nilai-nilai tradisional dari kulinernya, ternyata masih mengandung kontestasi ideologis dibaliknya. Sebagaimana dengan yang ada di ketiga sastra kuliner tadi, novel Aruna dan Lidahnya kali ini juga akan ditelisik dengan poskolonialisme yang mendasarkan pada tesis bahwa makna makan dan makanan yang terkandungdalam budaya "icip-icip" sebenarnya tidak dapat dilepaskan dari gaya hidup, citra citarasa, dan ideologi.

Dari segi hulu hingga hilir, aspek produksi hingga konsumsi, bahan pangan dan makanan sebenarnya penuh dengan muatan kepentingan kekuasaan. Di balik kelumrahan makanan dalam kehidupan keseharian, pangan mengandung pertanyaan besar tentang kekuasaan dan status seperti yang ditunjukkan oleh Sidney W. Mintz dalam Sweetness and Power. The Place of Sugar in Modern History(1986).Dan Jurafsky dan Yoshiko Matsumoto (2017) menyebut Sidney W. Mintz sebagai pelopor studi tentang hubungan kekuasaan, sosialmasyarakat dengan pangan.Penelusurannya tentang sejarah gula telah mengurai bagaimana gagasan-gagasan antar-budaya saling mempengaruhi, pengaruh ekonomi terhadap perubahan budaya, dan bagaimana makanan dan budaya memperoleh makna simboliknya.Munn (1986) berperan dalam mendedah penciptaan nilai simbolik sistem makanan. Di sisi lain, Sutton (2001) menggambarkan peran makanan dalam kontruksi sosial memori. Sutton (2001,p.170) mencoba untuk memahami bagaimana makanan menyampaikan ingatan dan bagaimana makan dan minum melahirkan dan mempertahankan kesadaran historis.

"What people eat, howand with whom, what they feel about food and why - even who they eatare of crucial significance to an understanding of buman society," papar Sceats (2000:1). Makna simboliklah-bukan biologis- yang menjadi signifikansi utama dari makan.Namun, signifikansi makna simbolik makan dan makanannya ini lebih banyak "dipahami" daripada diartikulasikan (Sceats, 2000,p.2), dalam bahasa Bourdieu (1984),sebagai representasi selera kelas. Pada diskursus ini sastra kuliner dapat dilihat sebagai ruang ekspresi pengalaman makan makanan, yang tidak hanya menggambarkannya sebagai pengalamanbiologis, terutama penjelajahan indera, tapi juga pada pengalamansosial budaya di ranah makan: di luar-di dalam, citarasa lokal-global, makan bersamasendiri, dan lain-lain. Novel Aruna dan Lidahnya (2014) karya Laksmi Pamuntjak ini menggambarkan ekspresi identitas kosmopolitan kaum urban melalui makanan.Wawasan dan minat terhadap gastronomi mendorong para kaum muda urban mengeksplorasi makanan lokal Nusantara.Namun, narator memperlihatkan bahwa makanan Nusantara belum memiliki posisi sejajar atau tepatnya masih mencari posisi dalam pertarungan selera di lidah kaum muda urban.

Aruna dan Lidahnya merupakan novel kedua Laksmi Pamuntjak yang diluncurkan pertama kali pada 13 November 2014.Sebelumnya, penulis yang lahir pada 22 Desember 1971 ini juga telah menerbitkan novel berjudul $A m b a$, yang mendapat sambutan yang hangat dari peminat sastra Indonesia dan mancanegara setelah diterjemahkan ke dalam bahasa Inggris dan Jerman. Karya fiksi lainnya adalah The Diary of R.S.: Musings on Art (2006). Ia juga menerbitkan Ellipsis (2005), The Anagram (2007), Perang, Langit dan Dua Perempuan (2006). Laksmi Pamuntjak juga 
merupakan seorang duta Indonesia dalam Poetry Parnassus/Cultural Olympiad pada 2012.Antara tahun 2009-2012, ia menjadi juri Prince Claus Awards. Novel Aruna dan Lidahnya bukanlah petualangan rasa pertamanya karena sebelumnya, penulis yang kini tinggal di Singapura ini telah merekam perjalanan panjang "icip-icip"-nya dalam empat edisi seri panduan makanan, The Jakarta Good Food Guide. Oleh karena itu, posisi "Aruna dan Lidabnya" penting sebagai representasi citra cita rasa kuliner lokal Indonesia di benak dunia kaum kosmopolit poskolonial semacam Laksmi Pamuntjak dalam sosok Aruna dan ketiga kawannya.

\section{METODE}

Kritik poskolonial dalam studi sastra berperan sebagai kerangka teori dan subjek kajian. Sebagai subjek kajian, kritik poskolonial mengkaji karya sastra yang dihasilkan oleh budaya yang merupakan respon terhadap dominasi kolonial. Sebagai kerangka teori, kritik poskolonial berupaya memahami bekerjanya ideologi kolonial dan antikolonial-bagaimana masyarakat yang pernah terjajah menginternalisasi nilai-nilai penjajah dan sekaligus resistensebagaimana direpresentasikan dalam teks sastra (Tyson, 2006,p.418). Untuk melihat representasi warisan kolonial itu dalam novel Aruna dan Lidabnya, dilakukan penelitian dengan close reading sebagaimana Hunter (2002,p.111) dan Foulcher (2005) mengkaji jejak kolonial dalam novel Salah Asuban dengan membaca kembali konteks "dunia" novel Salah Asuhan dan "dunia" Abdoel Moeis saat dia menuliskannya.

Di dalam Aruna dan Lidabnya, close reading memperlihatkan adanya ambiguitas dan paradoks di dalam diri Aruna dan ketiga kawannya yang menjadi representasi psikologis dari Laksmi Pamuntjak dan bangsa Indonesia pada umumnya. Dalam close reading Aruna dan Lidabnya ini dilakukan langkah-langkah sebagai berikut: pertama akan dilihat bagaimana pembacaan umum di awal-awal novel Aruna ini dibahas dengan pendekatan kajian kuliner poskolonial. Lalu dilakukan penelaahan dari sisi dalam pernyataan dan percakapan yang ada dalam novel ini dengan bolak- balik melihat dan merefleksikan konteks dunia novel Aruna dan Lidabnya dan dunia Laksmi Pamuntjak. Kehadiran sosok Aruna (dan dengan ketiga temannya, yaitu Bono, Nadezdha, dan Farish) dapat juga dilihat sebagai representasi ambiguitas dan paradoks dalam sosok diri Laksmi Pamuntjak yang terasa sebagai 'warga bangsa Indonesia yang terbayang', yang hidup di dua dunia kosmopolit yakni hidup di dalam novel di ruang kehidupan Jakarta dan dunia'Barat' dan di luar novel, yaitu Singapura, tempatnya tinggal di dunia nyata.

\section{HASIL DAN PEMBAHASAN \\ Mencicipi "Sastra Icip-Icip"}

Aruna dan Lidahnya menggoda banyak orang untuk ikut mencicipinya. Sari (2015) menelisik struktur dan makna citra kuliner lokal dalam novel itu. Aruna dan Lidabnya dinilai telah menggambarkan paradigma baru yang merupakan paradoks pandangan umum yang menganggap modernitas telah menggerus perhatian anak muda terhadap unsur-unsur lokal, terutama kuliner lokal.Tokoh-tokoh dalam novel ini mengaitkan kuliner lokal dengan identitas sosial budaya yang mengalami pergeseran akibat modernitas. Dengan demikian, menurut Sari, tampak bahwa mereka menunjukkan sikap lebih menghargai kuliner lokal dibandingkan dengan kuliner Barat. Hal inilah yang justru kontras dengan penilaian kritis sastra gastronomi dalam tulisan ini. Penulis mendapati bahwa mengangkat kuliner lokal sebagai subjek penceritaan dalam novel ini ternyata tidak dengan sendirinya menunjukkan kebanggaan terhadap kuliner lokal tersebut.

Pembicaraan lain tentang kuliner lokal lebih banyak terkait dengan usaha meningkatkan pariwisata. Salah satunya adalah penelitian Pitanatri (2016) yang berjudul "Inovasi Dalam Kompetisi: Usaha Kuliner Lokal Menciptakan Keunggulan Kompetitif di Ubud". Pembentukan citra kuliner lokal di Ubud sebagai destinasi wisata sangat dipengaruhi oleh generasi 
milenia, yaitu masyarakat yang lahir pada 1977-1994. Generasi milinea terutama berperan sebagai konsumen dan pembentuk image kuliner lokal. Sebagai konsumen, generasi milinea memiliki kecenderungan untuk menghabiskan uangnya pada produk yang menghasilkan rasa nyaman, terutama makanan. Peran milinea lainnya terkait dengan aktivitas mereka di media sosial.Konstruksi citra makanan Ubud sangat dipengaruhi oleh banyaknya unggahan "Ubud Food" atau "Ubud Culinary" di media sosial semacam YouTube.Dalam hal ini, posisi kaum muda urban lebih ditempatkan sebagai konsumen citarasa produk lokal dan "produsen" simbol-simbol budaya terkait makanan, terutama melalui media sosial, yang mempengaruhi selera masyarakat terhadap produk lokal sebagai produk wisata kuliner, sesuatu yang berjarak dengan hidup seharihari.

Berjarak dengan kuliner lokal ini pula yang menjadi bahan cerita "sastra icip-icip" seperti Aruna dan Lidahnya.Dalam resensinya, Damayana (2015) mengapresiasi novel ini dalam hal menginspirasi para pembaca untuk mencicipi beraneka ragam kekayaan kuliner Nusantara.Namun, ia menyayangkan bahwa sebagai novel kuliner, Aruna dan Lidabnya tidak menyajikan kedalaman "petualangan seru atau drama manusia dengan bumbu kuliner". Luasnya wawasan gastronomi sang novelis, yang memang merupakan penulis buku-buku kuliner yang populer, terlihat dalam deskripsi panjang lebar tentang aneka kuliner Nusantara dalam petualangan sang tokoh utama, Aruna. Namun, hal itu tidak menimbulkan kedalaman hubungan dengan pembaca karena pilihan-pilihan kuliner Aruna dan tokoh-tokoh lainnya tidak memberikan pengaruh yang besar dalam pembentukan plot novel.Berbagai peristiwa makan mereka hanyalah rangkaian "icipicip" yang menjadi salah satu latar petualangan Aruna dan teman-temannya ke berbagai daerah, bahkan sampai ke mancanegara.
Dalam tulisannya, Nitami (2016) mengurai motivasi di balik petualangan kuliner Aruna dan ketiga temannya, yaitu Bono, Nadezdha, dan Farish. Obsesi terhadap makanan merupakan benang merah yang mengikat persahabatan mereka selama bertahun-tahun. Sebuah "obsesi" dari kelas atas metropolitan poskolonial yang tak jauh dari mental tuan kolonialnya yang penuh dengan hasrat "quest for the exotic" (Heldke, 2008:3).Walaupun demikian, keempatnya memiliki latar berbeda yang mendasari obsesi terhadap makanan.Aruna terobsesi makanan karena kesendiriannya dan pencariannya atas sarana pembebasan diri dan sumber kebahagiaan. Nadezdha tidak dapat lepas dari makanan karena pekerjaannya sebagai penulis kuliner, gaya hidup, dan pertemanan. Sementara Bono, pekerjaannya sebagai chef dengan latar belakang pendidikan kuliner membuatnya hidup di seputar makanan. Tentu saja, gaya hidup dan pertemanannya sebagai seorang chef restoran kelas atasjuga mempengaruhi pandangannya terhadapmakanan. Farish sebenarnya ada di luar lingkaran ketiga temannya yang terobsesi dengan makanan.Pergaulan dekatnya dengan Arunalah yang akhirnya membuatnya menyukai makanan.Sayangnya, faktorfaktorpenentu kecenderungan seseorang terhadap makanan itu hanya terpaku pada tingkat psikologis personal.Konteks sejarah, kelas, sosial, dan budaya dalam tataran masyarakat yang melingkupi novel kuliner belum banyak dieksplorasi.

\section{Semangat Baru, Selera Lama}

Aruna dan Lidahnya merupakan cerita perjalanan Aruna sebagai seorang epidemologis yang menyelidiki menjangkitnya flu unggas di beberapa kota. Perjalanannya meliputi KotaBangkalan, Pamekasan, Palembang, Medan, Banda Aceh, Pontianak, Singkawang, Lombok, dan Mataram.Dalam perjalanannya itu, kuliner-kuliner lokal menjadi obsesi tersendiri selain menghimpun informasi tentang berbagai misteri seputar laporan 
kasus flu unggas di daerah-daerah itu.Kenyataannya, kasus-kasus flu unggas itu tidak selalu terkait dengan masalah kesehatan lingkungan, tetapi juga korupsi dan birokrasi yang disalahgunakan secara politis. Hal ini mempengaruhi perjalanan tokoh sebab ada titik saat Aruna ke luar dari pekerjaannya di OneWorld karena intrik politik yang melibatkan instansi pemerintah. Akan tetapi, unsur pokok lainnya dalam novel ini, yaitu makanan, justru tidak mempunyai peran signifikan dalam pembentukan cerita selain hanya sebagai kumpulan peristiwa petualangan mencicipi sajian makanan di sepanjang kota ala foodis dengan buku guide kuliner populer sebagai panduan mencari penghiburan. Baru di akhir cerita, makanan mengubah hidup Aruna karena ia memutuskan untuk menjadi investor di restoran temannya, Bono. Di sinilah ia mulai melangkah dari sekadar penikmat makanan menjadi pengusaha bisnis makanan. Namun, di sisi lain, akhir cerita juga menunjukkan bahwa makanan justru merupakan hal yang negatif dalam hidup Aruna. Aruna pun melakukan perubahan dengan membatasi makanannya, mengganti gulali menjadi salmon kukus meskipun menguras kantongnya lebih dalam (p. 384). Dia merasa hidupnya telah sempurna saat ukuran bajunya yang semula XL menjadi S.

Di sisi lain, perubahan pola makannya dapat menyiratkan bahwa gaya makan Baratlah yang sehat. Untuk menjadi sehat, Aruna merasa harus mengonsumsi salmon, ikan impor yang didengungdengungkan sebagai ikan paling berkhasiat oleh buku-buku masak terbitan luar negeri yang banyak diterjemahkan ke bahasa Indonesia.Gulali yang merupakan makanan tradisional Indonesia pun harus disingkirkan karena kandungan gulanya yang dinilai membahayakan kesehatan. Padahal, gulali yang dibuat dari gula jawa (aren/kelapa) bukanlah makanan berbahaya, bahkan berkhasiat (Soetanto, 1998,p.10).Yang asing sebagai yang lebih baik juga mewujud dalam kesukaan baru Aruna bersama Bono dalammelakukan eksperimenmengolah masakan Timur dengan memberinya sentuhan Barat, "sup serupa pindang patin yang diberi sentuhan Barat, salad gaya Prancis dengan sejumput semanggi" (p. 420). Dominasi citarasa Barat juga tampak dari otoritas selera yang dipegang oleh Bono.Penilaian Bono sering kali menjadi penentu kelebihan atau kekurangan suatu makanan lokal. Padahal, dalam penilaiannya tak kerap ia terpental dari konteks tradisi kuliner tradisional, contohnya ia merasa campuran gula jawa pada kombinasi bawang putih dan kecap pada banyak makanan tradisional, seperti rujak tolet, justru mengacaukan rasa. Padahal, gula jawa justru menjadi dasar bumbu utama dalam makanan Nusantara, sementara kecap hanyalah tambahan. Hal ini berbeda dalam konsep makanan Barat, yang memposisikan kecap atau saus sebagai unsur bumbu (condiment) utama sehingga tidak perlu penambahan bumbu lain agar tidak merusak rasa. Penilaian Bono semacam ini justru membuat Aruna makin inferior, "Dan sialnya penilaian ini sertamerta membuatku meragukan lidahku sendiri" (p.120).Dengan demikian, pergeseran dari cita rasa Timur ke Barat dinilai mampu mengubah makanan menjadi lebih sehat atau lebih bercita rasa dantentu saja-lebih berkelas.

Selain kecenderungan untuk menganggap makanan Barat atau makanan dari luar lebih baik, inferioritas bekas kaum terjajah juga muncul dari nada mengejek makanan lokal. Arunalah yang paling mewakili sikap ini dibandingkan dengan teman-temannya. Bono lebih sering bersikap proposional, berfungsi sebagai penyeimbang. Namun, sering kali narator tidak dapat menutupi sikap dan mentalitas bangsa poskolonial yang terjangkit mental inlander-mentalitas mimikiri yang meniru, memuja gaya, dan mengikuti pandangan dan pola-pola tuan kolonial mereka. Akan tetapi, bukan dalam spirit subversive dan mockery dalam psikologis kolonial yang ambivalen pada tuannya sebagaimana pandangan Bhabha (1997), melainkan karena rendah diri-sebuah mentalitas yang 
oleh Al-Qurtuby (2016) dipersalahkan karena "sikap fanatisme mereka terhadap bangsa lain itu diiringi dengan tindakan menafikan dan bahkan merendahkan bangsanya sendiri." Memang, di novel ini Bono, yang berlatar belakang pendidikan kuliner di New York, lebih sering menunjukkan sikap positif terhadap makanan lokal. Hal ini dapat dikarenakan pandangannya terhadap makanan lokal sebagai sesuatu "yang lain", jarak yang membuatnya antusias menghadapi "yang lokal" justru sebagai "yang asing" "yang exotic" bagi dirinya yang merupakan chef yang telah lama tinggal di New York dan London. Nada mencemooh makanan lokal ini dapat dilihat dalam kutipan berikut ( $p$. 154):

Sate Lalat yang begitu tersohor itu ternyata bukan sepenuhnya metafora: itu sungguh sate seukuran lalat. Dengan kata lain: kecil seupil. Penyajiannnya sama dengan sate ayam biasa, sepuluh tusuk, berlumur saus kacang campur kecap manis. Tapi ya itu, kecil seperti upil dan bikin aku naik darah.

"Emangnya apa yang kamu harapkan?’Tanya Bono sambil tertawa."Lalat beneran?Atau ayam yang dibuat dari lalat-seperti makanan vegan?"

Entah berapa foto yang telah dia ambil dengan iPad-nya. Aku bisa bayangkan tweet-nya: Yo. Behold. Lord of the Flies in the flesh. Atau:Fly Satay air. Atau Sate Upil.

"Laler kok pura-pura jadi ayam?" kata Farish ikut-ikutan, seolah dia tak ikut kecewa."Apa nggak cukup virus yang dia sebar?"

"Karena ayam lebih banyak lagi penyakitnya. Jadi lebih sehat makan lalat," kata Inda tergelak-gelak, jemarinya sibuk memilin kain merah tenda yang menaungi kami berempat, seolah dengan menyentuhnya warung itu akan menjelma restoran mewah. "Aku serius.Ini asli makanan terburuk yang pernah kulihat," kataku, masih dengan kejengkelan yang tak mainmain."Mana rasanya ginidoang."
Dari kutipan di atas, terlihat citra negatif sate lalat yang ditampilkan sebagai sesuatu yang menjijikan. Hal ini dibentuk dari asosiasi makanan tersebut dengan sesuatu yang lekat dengan kondisi yang kotor. Asosiasi ini tidak hanya muncul dari makanan itu saja yang menyerupai lalat yang suka berkerubung di tempat kotor, tetapi ambience (suasana) makan itu di warung sederhana yang dimaknai jauh dari tempat ideal untuk makan, “...jemarinya sibuk memilin kain merah, tenda yang menaungi kami berempat, seolah dengan menyentuhnya warung itu akan menjelma restoran mewah." Kesan negatif makanan lokal juga muncul di petualangan kuliner berikutnya, yaitu kikil kokot (hlm. 156) yang digambarkan sebagai makanan berlemak nan menjiijkkan. Citra buruk ini menjadi lebih intensif dengan penggambaran suasana tempat makan yang penuh lalat.Higinitas Barat atau modern benarbenar telah menjadi obsesi anak-negeri yang ditanamkan sejak masa kolonial (Dijk \& Taylor, 2011).Pencitraan makanan lokal sebagai makanan yang menjijikkan dan kotor terlihat dalam kutipan berikut:

Lima belas menit berlalu, dan kami mulai menyantap kikil kokot masingmasing.Aku tiba-tiba mati rasa. Hidangan itu disajikan nyaris dingin, dan sumsum yang harus dikais dari dalam tulang atau diseruput melalui sedotan terlihat seperti bagian otak yang terburai-ketika aku memasukkannya ke mulut, ia seperti lemak kotoran yang mengental di dalam dan sekitar mulut. Bibir, lidah, atap mulut, semuanya terkunci dalam gajih.

Akhirnya, aku menyerah.Tak lama kemudian, sepasukan lalat mengerubungi sisa makanan di mangkukku.Biarlah lalat memenangi kikil kokotku.

Hal lain yang mempengaruhi rendahnya citra makanan lokal adalah bahan makanan lokal yang sederhana dan terkesan murahan. "Pecel semanggi bukan hidangan yang dahsyat. Ia adalah makanan survival, makanan yang muncul dan menjamur 
karena bahan pangannya murah dan bisa ditemukan di mana-mana" (p. 159). Padahal hidangan pecel semanggi ala Surabaya ini sudah mulai langka karena sulitnya menemukan lahan tanaman semangginya. Penilaian yang buruk terhadap makanan lokal tersebut muncul karena parameter yang berasal dari citarasa adiluhung sebagai kritikus makanan. Sementara yang dianggap citarasa adiluhung di sini adalah seni kuliner Barat dan kelas menengah ke atas, ambivalensi Bono di novel ini seringkali mencoba menempatkan (appropriasi) dalam konteks sosial budaya lokal, sayangnya tidak tereksplorasi lebih oleh narator. Di satu sisi, Bono memuji sajian bebek Madura yang melampaui pengalaman kulinernya di Prancis, "Berkali-kali aku keliling bistrobistro di Prancis, belum tentu aku menemukan duck confit yang benar-benar oke. Padahal itu tradisi mereka. Eh, sekalinya aku ke Bangkalan, Madura, Negara Kesatuan Republik Indonesia, aku menemukan tekstur mirip confityang akan membuat chef Prancis mana pun terpana" (p.133). Ambivalensi Bono tampak dari obsesinya membuat olahan bebek-bebek bergaya Prancis dan Madura. "Aku jadi ingin membuat dua macam duck confit di restoranku," kata Bono."Gaya Prancis, yang sudah ada di menu, disajikan dengan kentang yang dipanggang di dalam lemak bebek, pammos de teree ala sarladaise, dan gaya Madura ini" (p. 134).Dengan demikian, penilaian terhadap makanan lokal sesungguhnya sulit untuk menjadi fair karena parameter yang dibentuk oleh "selera asing" diterapkan dalam mengukur "selera lokal".

Selain dibentuk dari penyuguhan makanan tersebut, citra ini diperkuat oleh suasana tempat makan yang sederhana dan diidentikkan dengan kotor. Kategori ideal sebuah tempat makan ala kota metropolitan dan tentu saja selera barat yang mencakup sejarah, pengelolaan, suasana, desain gedung, pelayanan, dan menu seperti yang digunakan Nadezhda dan Aruna (p.157) juga menyiratkan tidak berkelasnya sebagian besar destinasi petualangan icip-icip mereka.

Tahu nggak, jadi kritikus restoran itu nggak gampang, Run.

Emang gak ada yang pernah bilang gampang, Nadz.

Coba lu lihat kolom-kolom restoran di koran-koran ternama. Semuanya pendek,Run.Padahal, selain menyinggung sejarah, pemilik, konsep, suasana, servis, menu, pada akhirnya yang membedakan kolom satu dan kolom lainnya adalah mutu analisa makanannya. Nah, gimana kalau kita harus mengulas menu degustation yang terdiri atas sembilan sampai lima belas hidangan, yang semuanya seperti karya seni? Di sebuah restoran yang juga kaya sejarah, kaya detail, kaya segalanya.

Kenyamanan tempat makan sesungguhnya bersifat relatif. Menerima dan menghayati kesederhanaan tempat dan bahan makanan dapat memberikan rasa nyaman penikmat kuliner sejati.Petualangan kuliner justru menuntut kemampuan beradaptasi dengan rasa dan suasana kuliner lokal, tanpa ekspetasi berlebihan berdasarkan standar kuliner "asing". Hal ini dapat dilihat dalam catatan perjalanan kuliner dalam catatan perjalanan kuliner Jalansutrayang diprakarsai oleh Bondan Winarno.Kecintaan terhadap kuliner tradisional bukannya berarti cinta buta atau chaunivisme yang menutup kemungkinan kekecewaan pada masakan tradisional, namun hal ini harus dilandasi oleh kesadaran kultural atau penghargaan terhadap budaya sesuai dengan porsinya. Sebagai contoh, Mei, salah satu kontributor Panduan Makan-Makan dan Jalan-Jalan ala Jalansutra: Satu Keluarga Sejuta Cita Rasa (2014), menangkap adanya keluhan-keluhan tentang kurangnya variasi menu dan kelayakan untuk menjamu tamu dari mancanegara. Untuk itu, ia menawarkan alternatif rumah makan Payon, Kemang. Di sini kesederhanaan rumah makan tradisional di Jakarta justru menjadi kemewahan (p. 58).Hal ini berbeda dengan 
ekspresi-ekspresi dalam Aruna dan Lidahnya yang mengukur kenyamanan dengan indera pengecap Barat. Landasan penghargaan atas kekayaan budaya sendiri dalam komunitas Jalansutra ini terekam dalam catatan perjalanan Mei dalam merespons penyajian dan bahan pangan lokal yang kurang akrab dengannya sebelumnya (p.59)

\section{Nasi Cobek dapat dipilih menggunakan menu ayam goreng serai atau ikan bilis atau lidah goreng.Saya sempat penasaran kenapa namanya Nasi Cobek, mungkin menggunakan sambal cobek. Ternyata.... Sensasi kedua pada saat pesanan datang, sebuah cobek batu benar-benar diantar ke hadapan saya, dengan nasi putih di atasnya. Lalu ayam goreng, serai, dan tahu serta tempe goreng plus lalapan disajikan di piring terpisah. Sambalnya mana ya? Oh ternyata sambalnya ada di dasar nasi putih. Sambal itu dibuat di atas cobek, lalu baru ditaburkan nasi putih.Unik sekali ya?Rasanya juga unik.Saya tidak menyesal memilih menu itu.}

Petualangan ini tentu berbeda dengan keseharian kaum urban milenia itu di ibukota yang mementingkan citra pergaulan kelas atas dalam menentukan tempat makan (p. 195).

Orang-orang Pondok Indah akan tetap ke Siria 1 meskipun kena macet berjam-jam.

Karena memang begitulah perilaku konsumen kelas atas Jakarta Selatan.Di mana mereka kelihatan nongkrong sangat penting buat image.

...

Bisa nggak kamu bayangkan, menu ABCKitchen, di Jakarta! Persis seperti di New York!"

Bono-ku memang seorang chef tulen. Dihadapkan dengan masalah bersifat sosiologis, solusinya murni kuliner.

Kesimpulan Aruna dalam kalimat terakhir tersebut justru kontras dengan pendapat Bono. Sulit menganggap menu semata sebagai urusan perut tanpa mengaitkannya dengan pembentukan selera konsumen kelas menengah atas ini.Seperti yang diungkapkan oleh Bono sebelumnya, motivasi orang datang ke restoran itu justru terkait dengan citra tempat itu sebagai tempat berkumpulnya kelas atas.Citra ini terkait dengan tempat dan penyajian yang mewah, serba bersih.Menu internasional menjadi standar kelas atas. Orang yang memiliki akses untuk turut menikmati fasilitas kelas atas di sana secara otomatis mendapat pengesahan sosial sebagai bagian dari kelompok elite itu. Hal ini diperkuat dengan pernyataan Nadezhda tentang foodism (p. 85).

Foodism pada akhirnya masalah kelas. Meskipun Brillat-Savarin adalah dewa gue, gue nggak pernah terlalu setuju sama kata mutiaranya, 'You are what you eat,' Bayangin kalau ge bisa masuk dan memahami otak Bono yang ruwet itu hanya dari menelaah makan paginya. Tapi ketika orang melihat daftar restoran-restoran yang telah gue kunjungi di alam semesta ini, mereka tahu bahwa gue punya duit. Dan bahwa gue seorang snob, karena menolak makan curly fries di sebuah fast food joint tapi bersedia makan truffledfries di restoran kelas atas.

Bentuk lain foodism dalam Aruna dan Lidahnya terlihat dalam pesta wine yang diadakan oleh Bono di restorannya. Bono mengundang Aruna untuk hadir dalam acara uji citarasa wine yang dihadiri oleh kalangan atas itu. Aruna tampak sangat menikmati acara kuliner itu. Dalam hal ini, dapat dipertanyakan faktor yang paling mempengaruhi penilaian selera pada acara winetestingitu, apakah "kecanggihan lidah" atau suasana kelas atas yang membuatnya takjub. Hal ini meimbulkan ekspresi berbeda dengan petualangannya mencicipi kuliner lokal (p.386)

Aku dan kedua perempuan sosialitas itu menonton keempat laki-laki itu mengguncang-guncang wine di dalam 
gelas mereka sebelum membawa gelas itu ke hidung mereka, menghirup aroma minuman itu dalam-dalam lalu mereguknya. Kecuali Bono, yang mengenakan baju chef-nya, mereka semua mengenakan jas yang tampak mahal dengan saputangan sutra yang menyembul dari kantong di dada.

Mereka terus-terusan berbahasa Inggris. Di depan mereka terletak tiga gelas wine kosong.

Perbedaan kelas dan bentuk-bentuk identitas sebagai pembentuk kebiasaan makan manusia, sebagaimana dikemukakan Jeffrey M. Pilcher dalam Food in World History (dalam Rahman, 2016,p. 55), telah berkembang sepanjang sejarah peradaban manusia.Fadly Rahman secara komprehensif menguraikan sejarah makanan Indonesia dalam bukunya Jejak Rasa Nusantara (2016)."Budidaya” selera makan di Hindia mengikuti selera orangorang Eropa.Setelah kemerdekaan, gastronom seperti Chailan Sjamsu berusaha menepis ragam kemewahan dalam gaya hidup kolonial. Ia mempopulerkan makanan daerah (regional dish) (p. 219) dengan mendorong pemanfaatan sumber pangan lokal dan mengkesampingkan gengsi pemakaian bahan mahal seperti mentega dan terigu. Dalam penerbitan buku masak Masakan djeung Amis-Amis pada 1951, Balai Pustaka membuat rumusan "masakan kita" untuk memisahkan diri dengan "citarasa yang dianggap dari luar Indonesia” (p. 232).

Sebelumnya, pada masa kolonial, selera makan ala Eropa berhasil memukau kalangan ningrat pribumi sebagai hasil pendidikan yang mereka terima. Bahkan, dalam suratnya kepada Ny. R.M. Abendanon-Madri tertanggal 23 Juni 1902, Roekmini (adik Kartini) mengungkapkan bahwa seni memasak ala Eropa merupakan puncak kemajuan (p. 150). Lingkungan ningrat keluarga Kartini membuatnya tidak asing dengan selera makan Eropa.Kartini pun mengikuti jejak para perempuan Eropa yang menuliskan resep-resep masakan di samping cita-citanya mendirikan sekolah keterampilan memasak.Keinginan Kartini ini didorong oleh hasratnya untuk menjembatani kesenjangan antara budaya makanan di kalangan ningrat dengan rendahnya pengetahuan dan sumber bahan pangan di kalangan rakyat jelata (p. 152).

Setelah sekolah perempuan makin merebak di berbagai daerah, media perempuan pun bermunculan seperti Poetri Hindia yang terbit pada tahun 1908.Staf redaksi mencakup personel pribumi dan Eropa memungkinkan pertukaran resepresep makanan di antara mereka.Penyebaran resep melalui media seperti Soenting Melajoe bukan hanya membuat kaum pribumi belajar masakmemasak dari orang-orang Eropa, melainkan orang-orang Eropa juga turut menyerap pesona masakan Nusantara seperti rendang (p. 165).Pada masa berikutnya, resep-resep masakan Tionghoa menjadi prioritas penerbitan percetakan buku Lie Tek Long. Hal ini berkaitan dengan mengemukanya "identitas ketionghoaan dalam diri perempuan Peranakan" seiring terbitnya Tiong Hwa Wi Sien Popada (p.167).

Perpaduan citarasa kosmopolit - Pribumi, Arab, Tionghoa,dan Eropatersaji dalam buku masak karya Kardinah, adik Kartini yang terbit pertama kali pada tahun 1918.Iapun memodifikasi berbagai olahan dari Eropa dan dari daerah yang lain di Nusantara dengan pemahamannya yang mendalam mengenai pengelohan makanan. Dengan demikian, makanan asing yang kurang disukai dapat digubah sesuai dengan bahan dan selera pribumi.Selain melalui penerbitan buku masak, sekolah keputrian dengan kursus memasaknya pun makin meningkatkan pengetahuan masakmemasak terutama di kalangan perempuan ningrat (hlm.176).R.A. Soewardi merupakan salah seorang perempuan ningrat yang menyerap berbagai pembentukan selera itu.Ia mereproduksinya melalui buku Tjara Walandi (1937). Buku yang berisi berbagai resep olahan makanan Belanda ini merupakan idealisasi selera 
orang Jawa yang saat itu makin banyak menggemari makanan Belanda (p. 177-178).

Ada perbedaan mendasar dengan apa yang dialami para perempuan ningrat Jawa dan elite peranakan masa kolonial yang hidup dalam realitas hibrid budaya Jawa yang kosmopolit di atas dengan apa yang dialami oleh tokoh-tokoh dalan novel Aruna dan Lidabnya. Dari buku-buku resep yang mereka buat dan terbitkan tampak bahwa kesadaran kosmopolit yang menempatkan identitas menu masakan Jawa maupun Peranakan seimbang dan bersanding dengan menu Barat (Walandi/Eropa). Sedikit mirip dengan Bono yang terpana dan terinspirasi dengan citarasa lokal, para gastronomer sosialita masa kolonial ini sangat tertarik dengan menu Barat dan berksperimen menyesuaikan dengan lidah tradisional mereka. Dari tata layout di buku-buku menu-menu kosmopolit dan hibrid itu, tak ada nada merendahkan dan meninggikan menu mana yang inferior maupun superior. Kosmopolitanisme kaum urban Zaman Now (masa kini) ternyata berbeda nuansanya dengan kosmopolitanisme di zaman Kartini meskipun benih keminderan itu telah tampak ketika Kartini memuji masakan Eropa dan mempersoalkan kulitnya (Yulianto, 2007). Meskipun demikian, pengalaman gastronomi atau icipicip kuliner pada zaman jadul (zaman dulu) ala Kartini dan Aruna di zaman kekinian tampak jauh berbeda rasanya. Kehadiran bangsa walanda (Eropa) bersama para petualang kuliner zaman jadul kolonial lebih nyata. Oleh karenanya, sajian buku kuliner itu memang disajikan untuk memberi pengalaman pada sosok-sosok yang riil. Sementara Aruna dkk. seperti terbayangi oleh citraan dan nuansa Barat didalam dirinya sendiri. "Walanda" itu tidak hadir secara riil, bahkan mereka sebenarnya telah pergi, mereka tak hadir dalam realitas keindonesiaan masa kekinian. Namun, bayangan mereka tampak begitu nyata menguasai dan mendominasi selera Aruna dkk. Terlebih lagi, ironisnya, di bawah kesadaran mereka, Aruna dkk. menjadikan lidah mereka merepresentasi lidah walanda itu sendiri.

Bukan tidak kebetulan jika novel yang ditulis selama satu setengah tahun dan terbit pada 2014 ini memiliki nuansa euforia diskursus perkulineran Indonesia saat itu yang didorong oleh Kementerian Pariwisata dan Ekonomi Kreatif Indonesia pada masa Menteri Mari Elka Pangestu (2011-2014). Euforia itu ingin mewujudkan imajinasi kuliner bangsa Indonesia sebagai bagian dari dunia dalam dunia kulinernya-bangsa yang tidak lagi dilihat sebelah mata oleh dunia, bangsa yang tidak (merasa) tertinggal. Tak mengherankan pula bila Laksmi Pamuntjak yang juga dibesarkan di keluarga "Balai Pustaka" dari darah kakeknya dan terbiasa dengan hidup di dua bahasa (Inggris dan Indonesia) memiliki apa yang oleh Romo Mangunwijaya sebagai mentalitas "Indo" dalam ke Indonesiaan dalam "berpikiran dan bercitarasa". Aruna adalah representasi bangsa Indonesia yang Mangunwijaya katakan,"pada dasarnya memang adalah manusia-manusia Indonesia, tetapi dengan tekanan berat pada bagian kata Indo tadi." Realitas mental yang dilihat oleh Mangun sebagai hal yang menyedihkan namun normal dan tidak perlu dinilai negatif (dalam Hunter, 2002,p.112, ft.2).

\section{SIMPULAN}

Merujuk pada hasil temuan dapat disimpulkan bahwa dalam pembacaan close reading tampak ada ambiguitas dan paradoks yang muncul. Di satu sisi, Laksmi sendiri ingin menuturkan dalam novelnya kisah perjalanan, persahabatan, kuliner, dan isu flu unggas untuk memberi pesan bahwa makanan berperan sebagai pemersatu bangsa, seperti yang diutarakan oleh Laksmi Pamuntjak pada acara Media Gathering di Jakarta, Rabu (5/11/14, lihat Rahmawati, 2014). Di sisi lain, ada harapan dan imajinasi idealis yang terseok kandas saat ingin mengarahkan bahwa 'semestinya' kuliner Indonesiapun dapat lebih meng-'Indo' alias sejajar dengan citarasa standar dunia internasional atau Barat. Apa mau dikata 
bahwa kata semestinya (should be) dan realitasnya (it is) selalu paradoksal. Aruna dalam telaah Mangunwijaya adalah satu dari "Masyarakat [manusia] Indo, yakni masyarakat yang dalam penghayatan realita hidup dan kebudayaannya terbelah; lebih dari itu, alienated. Setengah asing terhadap diri sendiri, apalagi situasi dan keadaan sekelilingnya. Demikian kita semua." (Mangunwijaya, 1986, p.104).

Dengan demikian, pengalaman mencecap rasa terbentuk dari hubungan bahasa, kelas, dan identitas. Bahasa sebagai ekspresi kebudayaan dan penyebaran pengetahuan berperan besar dalam membentuk citra kuliner.Konstruksi kolonial yang membentuk inferioritas bekas masyarakat terjajah di segala aspek kehidupan, terutama bidang kuliner, perlu terus dikritik sebagai bentuk apresiasi terhadap keragaman budaya Nusantara. Memang, kajian Aruna dan Lidabnya ini merupakan salah satu wujud penghargaan terhadap karya anak bangsa yang mengangkat kekayaan khazanah kuliner lokal dalam karya sastra. Namun, selain yang eksplisit, perlu juga melakukan penggalian pada unsur-unsur di balik karya ini, terutama paradoks di balik representasi citra kuliner lokal itu. Masa poskolonial dan revolusi keindonesiaan ternyata membuat bangsa ini menjadi bangsa yang paradoks, bangsa yang ingin mengunggulkan jatidirinya namun sekaligus minder. Memuja segala yang Barat seakan lebih baik dan menista bangsa sendiri yang dirasa udik dan kampungan. Tarikan benci dan rindu pada kedua kutub itu tampak jelas dari kisah perjalanan icip-icip kuliner di novel Laksmi Pamuntjak ini. Alih-alih menempatkan kuliner lokal menjadi pusat identitas, Aruna dkk. malah terkesan merusak citraan citarasa kuliner lokal mereka sendiri. Namun, jika dilihat dalam segi positifnya, mungkin Laksmi Pamuntjak yang merupakan penulis buku destinasi kuliner yang hidup di dunia kosmopolitan kekinian ini ingin membangun otokritik atas kondisi dunia kuliner Indonesia yang tidak jauh beranjak menuju pasar dan masyarakat yang ingin dan hidup di dunia modern: yang bersih, sehat, dan berkelas.

\section{DAFTAR RUJUKAN}

Al-Qurtubi, S. (2016).Indonesia: Bangsa Kuli, Mental Inlander?.Diakses pada tanggal 31 Januari 2018dari http://www.dw.com/id/bangsakuli-mental-inlander/a-19479755.

Alvarez, L. (2018). Colonization, Food, and the Practice of Eating. Diakses pada tanggal 1 Februari 2018 dari http://www.foodispower.org/ colonization-food-and-the-practiceof-eating/.

Bhabha, H. (1997). Of Mimicry and Man.Tensions of Empire.Berkeley: University of California Press.

Bourdieu, P. (1984). Distinction: A Critique of the Social Judgement of Taste. (Trans. Richard Nice). Cambridge Mass: Harvard University Press.

Bramantio.(2013). Sastra Kuliner: Evolusi Gastronomi ke Gastrosofi Dalam Tiga Cerpen Indonesia. Jentera Vol. 2 No. 1 Juli 2013.

Dayamana, G.P. (2015). Resensi buku: Aruna dan Lidahnya karangan Laksmi Pamuntjak".Diakses pada 27 Desember 2017 dari https://gitaputridamayana.wordpres s.com/2015/01/12/resensi-bukuaruna-dan-lidahnya-karangan-laksmipamuntjak/

Dijk, K. V., \& Taylor, J. G. (2011). Cleanliness and Culture: Indonesian Histories. (pp. xii+-204). Brill.

Foulcher, K. (2005). Biography, history and the Indonesian novel: Reading Salah Asuhan. (Bijdragen tot de taal-, landen volkenkunde). Journal of the Humanities and Social Sciences of Southeast Asia, 161 (2-3), 247268.https://www.researchgate.net/p ublication/41017179_Biography_his tory_and_the_Indonesian_novel_Re ading_Salah_Asuhan 
Heldke, L. (2008). Let's Cook Thai: Recipes for Colonialism. Food and Culture: $A$ Reader. P. Van Esterik Ed. Routledge.

Hunter, T. (2002). Indo as other: Identity, anxiety and ambiguity in "Salah Asoehan". Clearing A Space: Postcolonial readings of modern Indonesian literature, 109-43.

Jurafsky, D., \& Matsumoto, Y. (2017). Think 53: Food Talks. 11 Mei 2017. Diakses pada 20 Januari 2018 dari: https://web.stanford.edu/class/thin k53/sugar17.pdf..

Mangunwijaya, YB. (1986). Menghadapi Budaya Pasca-indonesia dan Pascaeinstein.Makalah pada Temu Budaya DKJ. Jakarta: DKJ.

Mei. (2014). Payon Kemang.Dalam Panduan Makan-Makan dan Jalan-Jalan ala Jalansutra: Satu Keluarga Sejuta Cita Rasa. Tangerang: Penerbit Literati.

Mintz, S. W. (1986). Sweetness and Power: The Place of Sugar in Modern History. (n.c): Penguin.

Montanari, M. (2006). Food is culture. Columbia University Press.

Munn, N. (1986). The Fame of Gawa:A Symbolic Study of $V$ alue Transformation in a Massim [Papua New Guinea] Society. Cambridge: Cambridge University Press.

Nitami, N. (2016). Obsesi tokoh utama terhadap makanan dalam novel Aruna dan Lidahnya karya Laksmi Pamuntjak.Dialektika 3 (1). 2016. Diakses dari: http://journal.uinjkt.ac.id/index.php /dialektika/article/view/4182

Pamuntjak, L. (2014). Aruna dan Lidahnya. Jakarta: Gramedia Pustaka Utama.

Pitanatri, P.D.S. (2016). Inovasi dalam kompetisi: usaha kuliner lokal menciptakan keunggulan kompetitif di Ubud". Jumpa, Vol.3(1), Juli 2016. Diakses pada 15 April 2018 dari https://ojs.unud.ac.id/index.php/ju $\mathrm{mpa} /$ article/view/23026

doi: https://doi.org/10.24843/JUM PA.2016.v03.i01.p01.
Poerwanto, H. (1999). Asimilasi, Akulturasi, dan Integrasi Nasional. Humaniora, 11(3), 29-37. Diakses dari: https://journal.ugm.ac.id/jurnalhumaniora/article/view/668https:/ / doi.org/10.22146/jh.v11i3.668

Rahman, F. (2016). Jejak Rasa Nusantara: Sejarah Makanan Indonesia. Jakarta: Gramedia Pustaka Utama.

Rahmawati, Y. (2018). Aruna dan Lidahnya novel terbaru Laksmi Pamuntjak. Diakses pada 02 April 2018dari http:// bisniswisata.co.id/ arunadan-lidahnya-novel-terbaru-laksmipamuntjak/

Sari, W.R. (2015). Citra kuliner lokal dalam novel aruna dan lidahnya karya Laksmi Pamuntjak: tinjauan sosiologi sastra. Skripsi. Universitas Airlangga.

Sceats, S. (2000). Food, Consumption and the Body in Contemporary Women's Fiction. Cambridge University Press.

Soetanto, N. E. (1998). Teknologi Tepat Guna Membuat Gula Kelapa Kristal. Yogayakarta: Kanisius.

Sutton, D. E. (2001). Remembrance of Repasts: An Anthropology of Food and Memory. Berg Publishers.

Tyson, L.(2006). Critical Theory Today: A User Friendy Guide: New York. LondonNew York:Routledge. Diakses dari: http:/ / efford.weebly.com/uploads/ 1/3/8/3/13833564/critical-theorytoday_3.pdf

Utami, S. (2012). Mimikri dalam Kuliner Indonesia melalui Kajian Poskolonial.Prosiding The $4^{\text {th }}$ International Conference on Indonesian Studies: Unity, Diversity, and Future. Bali, 9-10 Februari 2012.https://icssis.files.wordpress.co m/2012/05/09102012-64.pdf

Yulianto, V. I. (2007). Pesona "Barat": analisis kritis-historis tentang kesadaran warna kulit di Indonesia. Yogyakarta: Jalasutra. 